\title{
Masa Emerging Adulthood pada Mahasiswa: Kecemasan akan Masa Depan, Kesejahteraan Subjektif, dan Religiusitas Islam
}

\author{
Received February 12, 2020 | Accepted June 21, 2020
}

\author{
Fera Hayatun Qolbi* \\ qferahayatun@gmail.com
}

Sitti Chotidjah

u_see@upi.edu

\author{
Ariez Musthofa \\ ariez.musthofa_pei@upi.edu
}

Universitas Pendidikan Indonesia

\begin{abstract}
This study aims to report about the effect of future anxiety on subjective wellbeing of the emerging adulthood with religiosity as a moderator for students at the Universitas Pendidikan Indonesia Bumi Siliwangi. This research uses a quantitative approach with a moderated causal method. The sample in this study were 300 final-year students at Universitas Pendidikan Indonesia. The sampling technique in this study uses accidental sampling. The instruments used are Future Anxiety Measurement, Satisfaction with life, Positive and Negative Affect Schedule (HEAT), Centrality of Religiousity Scale (CRS), Muslim Religiousity Scale (MRS) and A Psychological Measure of Islamic Religiousness. The analysis technique used is simple regression and Moderated Regression Analyze (MRA). The results showed that the moderator variable of religiosity showed insignificant results.. So it can be said that religiosity cannot moderate the influence of anxiety about the future on subjective well-being at the final year students of Universitas Pendidikan Indonesia.

Keywords: Future Anxiet; Moderation; Religiosity; Subjective Well-being,
\end{abstract}

\begin{abstract}
Abstrak. Penelitian ini bertujuan memaparkan pengaruh kecemasan akan masa depan terhadap kesejahteraan subjektif masa emerging adulthood dengan religiusitas sebagai moderator pada mahasiswa Universitas Pendidikan Indonesia Bumi Siliwangi. Penelitian ini menggunakan pendekatan kuantitatif dengan metode kausal yang dimoderasi. Sampel dalam penelitian ini yakni 300 mahasiswa tingkat akhir Universitas Pendidikan Indonesia dengan menggunakan accidental sampling. Instrument yang digunakan adalah Future Anxiety Measurement, Satisfaction with life, Positive and Negative Affect Schedule (PANAS), Centrality of Religiousity Scale (CRS), Muslim Religiousity Scale (MRS) dan A Psychological Measure of Islamic Religiousness. Teknik analisis yang digunakan regresi sederhana dan Moderated Regression Analyze (MRA). Hasil penelitian menunjukkan bahwa variabel moderator religiusitas menunjukkan hasil yang tidak signifikan. Sehingga dapat dikatakan bahwa religiusitas tidak dapat memoderasi pengaruh kecemasan akan masa depan terhadap kesejahteraan subjektif pada mahasiswa tingkat akhir Universitas Pendidikan Indonesia.

Kata Kunci: Kecemasan akan Masa Depan; Kesejahteraan Subjektif; Moderasi; Religiusitas.
\end{abstract}

\section{PENDAHULUAN}

Emerging adulthood mulai terjadi pada usia transisi individu mulai merancang mengenai aturan dan ekspektasi yang berkaitan dengan karir atau pendidikan, dan hubungan romantis yakni usia 18-20 tahun dan puncaknya terjadi pada usia 20-25 tahun usia rata-rata 
mahasiswa Strata-1 di Indonesia (Arnett, 2000 \& Murphy 2011). Individu yang ada di masa ini biasanya mengalami kebimbangan, ketidakpastian, frustasi dan rasa tidak aman dikarenakan mereka merasa belum menjadi dewasa tapi bukan lagi remaja (Martin, 2016). Dewasa awal biasanya menunjukkan ketidaknyamanan dan kekhawatiran tentang memilih sekolah atau pekerjaan (Kim, Kim, \& Ki, 2014). Ketidakpastian dan kebimbangan yang terjadi pada individu ini menimbulkan ketidakstabilan baik dalam segi emosi ataupun kognitif. Periode transisi membawa risiko yang lebih tinggi dari peningkatan kecemasan yang dapat memicu timbulnya atau kambuhnya gangguan kejiwaan (Auerbach et al., 2016; Blanco et al., 2015).

Periode emerging adulthood muncul pada masa dewasa awal yang ditandai oleh pengalaman-pengalaman yang mengubah hidup, termasuk kehidupan semasa kuliah (Gutter \& Copur, 2011). Tugas mahasiswa selain mulai mengambil tanggung jawab sendiri mengenai kehidupannya, mereka juga harus mempertanggungjawabkan kehidupan akademiknya. Kehidupan mahasiswa atau beban mahasiswa terjadi pada akademis, keuangan, homesick, hubungan sosial, pikiran mengenai masa depan dan kesehatan fisik (Beiter et al., 2015). Hal ini yang memunculkan stress berlebih pada mahasiswa, sehingga stress berlebih ini seringkali menimbulkan kecemasan (Lindsey, 2014). Kecemasan pada mahasiswa akan meningkat ketika mereka berada pada tahun terakhir perkuliahan (Ozen, Ercan, Irgil, \& Sigirli, 2010).

Berdasarkan survei yang dilakukan oleh Badan Pusat Statistik dalam penelitian indeks kebahagiaan di Jawa Barat. Indeks yang cukup dominan adalah mengenai kecemasan dan kekhawatiran yaitu sekitar 62,5\% untuk indikator tidak cemas dan khawatir. Angka ini menunjukkan indikator terendah sehingga dapat disimpulkan bahwa aspek ini yang lebih banyak memengaruhi kecilnya indeks kesejahteraan di Jawa Barat (Badan Pusat Statistik). Tingkat kecemasan yang tinggi di Jawa Barat salah satunya terjadi pada masa dewasa awal atau pada usia jenjang perkuliahan.

Tuntutan dan tekanan sosial mengenai norma, nilai hidup yang harus dipenuhi membuat kecemasan pada mahasiswa menjadi lebih tinggi (Martin, 2016). Gangguan kecemasan menjadi hal penting karena gangguan ini dianggap menjadi gangguan kejiwaan yang paling umum terjadi pada orang dewasa (Beiter et al., 2015). Kecemasan merupakan perasaan yang timbul dikarenakan kekhawatiran yang tidak normal terhadap sesuatu yang mungkin terjadi di masa depan sehingga berpengaruh terhadap aspek psikologis dan fisiologis (Akca, 2011). Kecemasan yang sering muncul pada mahasiswa adalah kecemasan mengenai pemikiran masa depan (Archuleta, Dale, \& Spann, 2013; Damer, Latimer, \& Porter, 2010; Zaleski, 1996). Kecemasan masa depan merupakan kondisi dimana terbentuknya perasaan takut, ketidakpastian, dan kekhawatiran yang didasarkan pada representasi kognitif dari peristiwa negatif dimasa depan (Miloyan, Pachana, \& Suddendorf, 2014; Zaleski, 1996).

Kekhawatiran akan kegagalan dalam mencapai tuntutan dan keinginan ini menimbulkan kegelisahan dan ketegangan yang membuat individu merasa cemas (Hinkelman \& Luzzo, 2007). Media sosial juga terkadang menunjukkan apa yang telah didapatkan oleh orang lain yang berhubungan dengan individu sehingga menyebabkan semakin tingginya kecemasan. Kecemasan yang terjadi dapat menimbulkan kepuasan hidup yang rendah (Saber, Mahmoud, Staten, Hall, \& Lennie, 2012). Kecemasan masa depan yang tinggi pada individu mampu menurunkan kepuasan hidup karena kecemasan merupakan 
emosi negatif yang terjadi pada individu. Individu pada masa emerging adulthood yang mengalami kecemasan seringkali menunjukkan tingkat kemarahan, kesedihan, dan kelelahan yang lebih tinggi dengan tingkat kebahagiaan dan kesejahteraan yang lebih rendah (Henker, Whalen, Jamner, \& Delfino, 2002). Jadi kegelisahan dan kecemasan menurunkan kesejahteraan subjektif individu yang tumbuh secara fisik, psikologis, dan sosial. Berdasarkan penelitian yang dilakukan oleh Steinmayr, Crede, McElvany dan Wirthwein (2016) menyebutkan bahwa kecemasan merupakan emosi negatif yang jika emosi tersebut tinggi maka akan menurunkan kesejahteraan subjektif, sedangkan ketika kecemasan diatasi dan emosi negative menurun maka emosi positif akan muncul sehingga dapat meningkatkan kesejahteraan subjektif. Hal ini menggambarkan bahwa kedua komponen kecemasan berpengaruh negatif terhadap kedua komponen kesejahteraan subjektif (Steinmayr, Crede, McElvany dan Wirthwein, 2016).

Kecemasan pada individu harus bisa diatasi agar dapat meningkatkan kesejahteraan individu, salah satu caranya adalah dengan religiusitas (Cohen et al., 2005). Religiusitas pada umumnya dapat menjadi faktor penting dalam memandu individu melakukan proses coping dari stres yang dialaminya (Soleimani, Lehto, Negarandeh, Bahrami, \& Chan, 2016). Religiusitas berpengaruh terhadap perilaku dan value yang dipegang oleh individu serta memiliki peran dalam menyesuaikan diri melewati peristiwa yang menegangkan yang membuat individu merasa cemas (Bowman, Beitman, Palesh, Perez, \& Koopman, 2009; Peteet \& Balboni, 1997). Pada penelitian terdahulu yang dilakukan oleh Abdel-khalek dan Lester (2010) menemukan bahwa religiusitas yang tinggi dapat menekan patologis kecemasan pada individu sehingga membuat individu lebih bahagia dan menikmati hidupnya. Pada penelitian ini juga ditemukan bahwa kepercayaan agama mampu membuat individu memandang makna yang berbeda bagi kehidupan sehingga dapat meningkatkan kesehatan psikologis (Abdel-khalek \& Lester, 2010). Oleh karena itu, perilaku religiusitas pada individu dengan melaksanakan praktik agama seperti berdoa, melakukan ritual keagamaan, melakukan sunah yang dianjurkan seringkali dianggap sebagai sesuatu hal yang memberikan kenyamanan dan makna dalam menghadapi ancaman hidup yang membuat seseorang stress dan cemas. Perbedaan penelitian ini dengan penelitian terdahulu adalah terletak pada fokus kecemasan yang diambil, yaitu kecemasan akan masa depan yang masih jarang diteliti terutama di Indonesia.

Berdasarkan latar belakang di atas, tujuan penelitian yakni memaparkan religiusitas dapat menjadi moderator bagi pengaruh kecemasan akan masa depan terhadap kesejahteraan subjektif. Hipotesis yang akan diuji dalam penelitian ini yakni religiusitas Islam dapat menjadi moderasi bagi pengaruh kecemasan akan masa depan terhadap kesejahteraan subjektif.

\section{METODE}

Penelitian ini menggunakan pendekatan kuantitatif metode kausal moderasi yang bertujuan untuk mengetahui pengaruh kecemasan akan masa depan (X) terhadap kesejahteraan subjektif (Y) dengan religiusitas Islam sebagai moderator. Partisipan dalam penelitian ini adalah 300 mahasiswa Universitas Pendidikan Indonesia angkatan 2016, 2015, dan 2014 dengan menggunakan pendekatan accidental sampling. Instrumen yang digunakan dalam penelitian ini adalah Future Anxiety Measurement berjumlah 15 item yang digunakan untuk mengukur kecemasan masa depan, Satisfaction with life berjumlah 5 item yang disusun 
oleh Diener, dkk pada tahun 1985 dengan reliabilitas 0.87 dan Positive and Negative Affect Schedule (PANAS) berjumlah 10 item yang disusun oleh Watson and Clark pata tahun 1999 yang digunakan untuk mengukur kesejahteraan subjektif, dan Centrality of Religiousity Scale (CRS) yang disusun oleh Huber \& Huber pada tahun 2012 dengan reliabilitas 0,83, Muslim Religiousity Scale (MRS) yang disusun oleh Albelaikhi pada tahun 1997b dengan reliabilitas 0,96 dan A Psychological Measure of Islamic Religiousness yang disusun oleh Raiya, dkk pada tahun 2008 yang digunakan untuk mengukur religiusitas muslim yang berjumlah 33 item.

Teknik analisis data menggunakan teknik analisis regresi yaitu regresi sederhana dan bertingkat. Data-data yang diperoleh dalam penelitian ini diolah dengan menggunakan Aplikasi SPSS untuk melakukan regresi linier sederhana dan metode moderated regression analysis (MRA) atau dikenal dengan regresi bertingkat (Ghazali, 2013).

\section{HASIL}

Pada bagian ini akan dijelaskan hasil dan pembahasan sesuai dengan hipotesis penelitian yaitu pengaruh kecemasan masa depan (X) terhadap kesejahteraan subjektif (Y) dan Religiusitas Islam (Z) memoderasi pengaruh kecemasan masa depan terhadap kesejahteraan subjektif.

\section{Hasil Analisis Regresi Sederhana, Regresi Berganda dan Moderated Analyze Regression} (MRA)

\begin{tabular}{|c|c|c|c|}
\hline \multirow{2}{*}{\multicolumn{4}{|c|}{$\begin{array}{l}\text { Tabel } 1 \text { Hasil Analisis Regresi Sederhana } \\
\text { Pengaruh Kecemasan Masa Depan terhadap Kesejahteraan Subjektif }\end{array}$}} \\
\hline & B & R Kuadrat & \\
\hline Konstan & 0,407 & & \\
\hline Kecemasan & $-0,385$ & 0,147 & 0,000 \\
\hline
\end{tabular}

Tabel model 1 menunjukkan p value sebesar 0,000 (<0.05) sehingga dapat dikatakan terdapat pengaruh kecemasan masa depan terhadap kesejahteraan subjektif. Kecemasan masa depan memberikan kontribusi sebesar 14,7\% (R kuadrat X 100) dalam menjelaskan nilai kesejahteraan subjektif yang dialami partisipan. Artinya masih terdapat 75,3\% predictor (variabel bebas lain yang bisa memengaruhi kesejahteraan subjektif.

Besaran pengaruh kecemasan masa depan terhadap kesejahteraan subjektif dapat dilihat pada kolom B pada tabel diatas, besaran pengaruh tersebut dapat dituliskan dalam persamaan regresi berikut ini.

$$
\mathrm{Y}=0.407-0.385 \mathrm{X}+\mathrm{e}
$$

Dalam persamaan regresi tersebut, 0,407 merupakan nilai konstan kesejahteraan subjerktif (Y), artinya jika kecemasan masa depan bernilai 0 atau tidak berpengaruh pada kesejahteraan subjektif maka kesejahteraan subjektif akan bernilai 0,407, kemudian -0,385 merupakan nilai koefisien kecemasan masa depan $(\mathrm{X})$ artinya setiap kenaikan skor kecemasan masa depan (X) akan menyebabkan penurunan skor kesejahteraan subjektif sebesar 0,385. Mengalami penurunan pada kesejahteraan subjektif hal ini dikarenakan hubungan antara kecemasan masa depan (X) terhadap kesejahteraan subjektif (Y) bersifat 
negatif. Sementara e merupakan residu atau sisa yang diartikan sebagai prediktor (variabel bebas) lain yang memiliki kemungkinan dalam memengaruhi nilai kesejahteraan subjektif.

Dengan demikian, hipotesis 1 yang menyebutkan bahwa terdapat pengaruh negatif kecemasan masa depan terhadap kesejahteraan subjektif mahasiswa tingkat akhir fase emerging adulthood di Universitas Pendidikan Indonesia, diterima.

Tabel 2 Hasil Regresi Kecemasan Masa Depan (X) dan

Religiusitas Islam (Z) terhadap Kesejahteraan Subjektif (Y)

\begin{tabular}{|c|c|c|c|}
\hline & $\mathbf{B}$ & R Kuadrat & Sig. \\
\hline Konstan & 0,055 & & \\
\hline Kecemasan & $-0,372$ & 0,147 & 0,000 \\
\hline Religiusitas Islam & 0.097 & 0,207 & 0,000 \\
\hline
\end{tabular}

Tabel 2 menunjukkan bahwa signifikansi kecemasan masa depan dan religiusitas Islam terhadap kesejahteraan subjektif sebesar $0,000 \quad(<0.05)$ yang berarti terdapat pengaruh kecemasan masa depan dan religiusitas Islam terhadap kesejahteraan subjektif. Berdasarkan data statistis di atas, kecemasan masa depan memberikan kontribusi sebesar 14,7\% ( $\mathrm{R}$ kuadrat $\mathrm{x}$ 100) dalam menjelaskan nilai kesejahteraan subjektif yang dialami responden, dan religiusitas Islam memberikan kontribusi sebesar $20,7 \%$ dalam menjelaskan nilai kesejahteraan subjektif.

Tabel 3 Hasil Analisis Regresi Berganda Religiusitas Islam Memoderasi Pengaruh Kecemasan Masa Depan terhadap Kesejahteraan Subjektif

\begin{tabular}{|c|c|c|c|c|c|c|}
\hline \multirow[t]{2}{*}{ Model } & \multicolumn{2}{|c|}{$\begin{array}{l}\text { Unstandardized } \\
\text { Coefficients }\end{array}$} & \multirow{2}{*}{$\begin{array}{c}\text { Standardized } \\
\text { Coefficients }\end{array}$} & \multirow[t]{2}{*}{ R Quadrat } & \multirow[t]{2}{*}{$\mathrm{t}$} & \multirow[t]{2}{*}{ Sig. } \\
\hline & B & $\begin{array}{l}\text { Std. } \\
\text { Error }\end{array}$ & & & & \\
\hline (Constant) & ,048 & ,093 & & &, 517 & ,606 \\
\hline $\begin{array}{l}\text { Kecemasan Masa } \\
\text { Depan }\end{array}$ & $\begin{array}{r}- \\
, 345 \\
\end{array}$ & , 100 &,- 347 & 0,147 & $-3,454$ & ,001 \\
\hline Religiusitas Islam & ,099 &, 022 & ,244 & 0,067 & 4,539 &, 000 \\
\hline $\begin{array}{l}\text { Kecemasan*Religiu } \\
\text { sitas }\end{array}$ &,- 008 & ,023 &,- 032 & 0,207 &,- 322 & ,748 \\
\hline
\end{tabular}

Tabel 3 menunjukkan bahwa kecemasan masa depan bisa menjadi prediktor bagi kesejahteraan subjektif dimana signifikansinya menunjukkan $0.001(<0.05)$. Lalu pada tabel 4.10 juga menunjukkan bahwa religiusitas Islam dapat menjadi prediktor bagi kesejahteraan subjektif dimana signifikansinya menunjukkan $0.000(<0.05)$. Sehingga hal ini menunjukkan bahwa religiusitas bisa menjadi prediktor terhadap kesejahteraan subjektif, kecemasan masa depan dapat menjadi prediktor bagi kesejahteraan subjektif.

Berdasarkan hasil analisis regresi bertingkat menunjukkan $p$ value sebesar 0,748 $(>0,05)$ artinya religiusitas Islam tidak berfungsi sebagai moderator dalam penelitian ini. Oleh karena itu, hipotesis yang menyatakan bahwa religiusitas Islam dapat memoderasi pengaruh kecemasan masa depan terhadap kesejahteraan subjektif pada mahasiswa tingkat akhir fase emerging adulthood di Universitas Pendidikan Indonesia, ditolak. 


\section{DISKUSI}

Berdasarkan hasil penelitian ini menunjukkan bahwa kecemasan masa depan dapat memengaruhi kesejahteraan subjektif dimana jika kecemasan masa depan pada individu tinggi maka kesejahteraannya rendah. Berdasarkan penelitian yang telah dilakukan oleh Lepp, A., dkk pada tahun 2014 mengenai hubungan performa akademik, kesejahteraan subjektif dan kecemasan menyatakan bahwa terdapat hubungan negatif antara kesejahteraan subjektif dan kecemasan. Lepp, A., dkk menyatakan bahwa penilaian kepuasan hidup dipengaruhi oleh keberhasilan dan kegagalan dalam kehidupan yang penting. Bagi mahasiswa akademik merupakan hal penting sehingga kecemasan dan kesusahan yang terjadi pada individu akan berdampak negatif bagi kepuasan hidupnya.

Pada penelitian ini kecemasan masa depan hanya memberikan konstribusi sebanyak 14,7\% dalam menjelaskan nilai kesejahteraan subjektif yang dimiliki oleh partisipan, kemungkinan alasan kontribusi kecemasan masa depan yang rendah ini adalah tingkat kecemasan masa depan pada mahasiswa fase emerging adulthood di Universitas Pendidikan Indonesia didominasi oleh kategori rendah yang hanya memiliki persentase selisih yang sedikit jadi tidak terlalu rendah. Apabila partisipan memiliki dominasi pada tingkat kecemasan masa depan yang sangat rendah dan kesejahteraan subjektif yang persentase tingginya lebih banyak, kemungkinan kontribusi kecemasan masa depan terhadap kesejahteraan subjektif dalam penelitian ini pun akan meningkat.

Hasil penelitian ini menunjukkan hasil yang sama dengan penelitian yang dilakukan oleh Abdul-khalek pada tahun 2010 yang menyatakan bahwa religiusitas, kesejahteraan subjektif dan kecemasan menjelaskan bahwa terdapat pengaruh yang signifikan antara religiusitas dan kesejahteraan subjektif, meskipun perbedaan budaya yang dimiliki oleh suatu daerah. Penelitian lainnya juga menyatakan bahwa hubungan performa akademik, kesejahteraan subjektif dan kecemasan menyatakan bahwa terdapat hubungan negatif antara kesejahteraan subjektif dan kecemasan (Lepp, dkk., 2011). Sehingga dapat disimpulkan bahwa kecemasan memberikan pengaruh negative terhadap kesejahteraan subjektif dan Religiusitas Islam dapat berpengaruh positif terhadap kesejahteraan subjektif.

Visualisasi interaksi variabel moderator dapat dilihat sebagai berikut.

Gambar Grafik Interaksi Variabel Moderasi

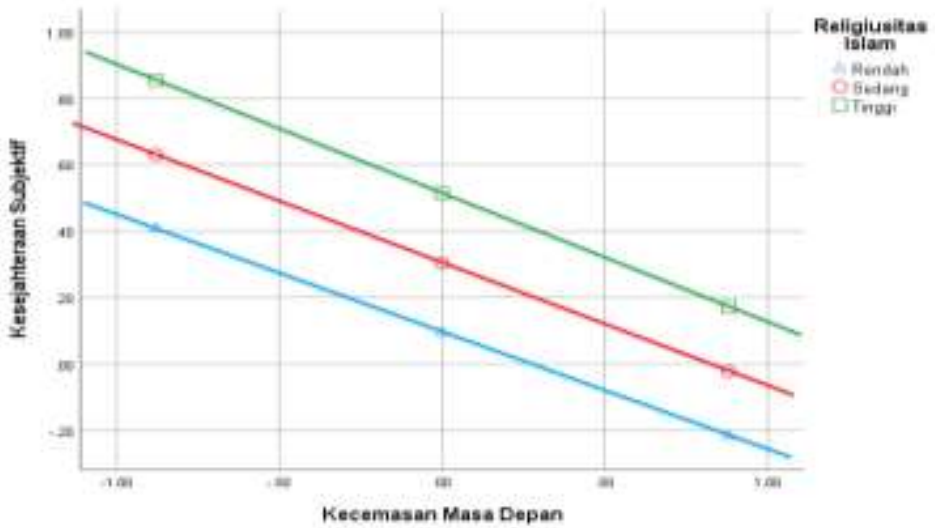

Grafik tersebut menunjukkan pengaruh religiusitas Islam dalam memoderasi kecemasan masa depan dan kesejahteraan subjektif. Terlihat bahwa garis-garis dalam grafik sejajar dengan sempurna. Hal ini berarti hubungan antara kecemasan masa depan dengan 
kesejahteraan subjektif ketiga level semuanya identik. Berdasarkan grafik dapat dijelaskan bahwa pada kelompok rendah tingkat kecemasan masa depan (X) rendah dan tingkat kesejahteraan subjektif (Y) lebih tinggi dibanding dengan kecemasan masa depan, lalu pada kelompok tinggi, tingkat kecemasan masa depan tinggi dan tingkat kesejahteraan subjektif lebih tinggi dibandingkan tingkat kecemasan masa depan, serta pada garis merah pun menunjukkan grafik yang sama. Garis yang pararel diatas jelas menunjukkan tidak adanya interaksi sehingga hasilnya tidak signifikan (Jose, 2013) Hal ini dikarenakan interaksi variabel yang digambarkan dalam grafik menunjukkan regresi antar kelompok sama, tidak memiliki perbedaan antar kelompoknya, sehingga variabel religiusitas Islam tidak dapat memoderatori pengaruh kecemasan akan masa depan terhadap kesejahteraan subjektif.

Hasil analisis regresi penelitian ini sesuai dengan penelitian dari Mohammadzadeh \& Najafi (2018) yang menunjukkan bahwa religiusitas dapat menjadi prediktor bagi kesejahteraan subjektif dimana ketika tingkat religiusitas Islam tinggi, tingkat kesejahteraan subjektif pun tinggi. Kepercayaan dan praktik agama dipercaya dapat mengurangi ketidakberdayaan dan kecemasan pada permasalahan. Kegiatan keagamaan seperti berdoa dapat memberikan kenyamanan, mengurangi rasa kesepian dan mengendalikan individu dalam menghadapi penyakit psikologis (Koenig et al., 2001). Selanjutnya, hasil penelitian (Abdel-Khalek \& Lester, 2012) menyatakan bahwa religiusitas memiliki hubungan positif dengan kesejahteraan subjektif dan memiliki hubungan negatif dengan kecemasan. AbuRaiya dan Agharia (2016) yang mendapatkan fakta bahwa bagi umat Islam patologi dan gangguan yang dihadapi dalam kehidupan merupakan ujian keimanan sehingga individu cenderung merasa tidak merasakan kesusahan dan ketegangan ketika menghadapi situasi yang negatif dan menganggap kecemasan adalah bagian dari kehidupan sehingga hal ini dapat meningkatkan kesejahteraan subjektif.

Jika dikaitkan dengan gambaran umum tingkat religiusitas Islam pada responden yang menyatakan bahwa tingkat religiusitas yang dimiliki responden adalah $50 \%$ memiliki religiusitas Islam yang tinggi dan 50\% menunjukkan religiusitas yang rendah sehingga hal ini kemungkinan menjadi faktor religiusitas tidak dapat memoderasi pengaruh kecemasan masa depan terhadap kesejahteraan subjektif. Berdasarkan penelitian yang dikemukakan oleh abdul-khalek bahwa religiusitas yang tinggi dapat berpengaruh terhadap tingkat kecemasan dan juga dapat berpengaruh terhadap tingkat kesejahteraan subjektif, sedangkan dalam penelitian ini religiusitas pada 300 partisipan tidak menunjukkan kecenderungan tingkat religiusitas yang tinggi sehingga tidak dapat menunjukkan peran religiusitas sebagai variabel moderator.

Faktor lain yang dapat memengaruhi religiusitas tidak dapat menjadi moderator yakni didasari pada penelitian yang dilakukan oleh Utami pada tahun 2012 bahwa religiusitas tidak dapat berpengaruh pada kecemasan dan kesejahteraan subjektif dikarenakan terdapat dua fungsi religiusitas dalam individu. Religiusitas sendiri digunakan individu untuk memenuhi aturan yang diberikan agama saja dan religiusitas yang digunakan oleh individu sebagai coping untuk meningkatkan kesejahteraan subjektif dan mengurangi perasaan negatif. Hal ini akan berpengaruh pada peran religiusitas itu sendiri. Peran religiusitas dalam kehidupan individu dipengaruhi oleh pengalaman hidup, pembelajaran dari orang tua, dan dari lingkungan sekitar. Salah satu faktor yang memengaruhi kecemasan masa depan, kesejahteraan subjektif, dan religiusitas Islam yakni lingkungan sosial/sekitar. Saat individu berada di lingkungan dengan religiusitas tinggi dan percaya bahwa segala sesuatu telah diatur 
oleh Tuhan, maka individu akan merasa bahwa Tuhan akan membantunya dalam menghadapi masalah dan memberikan kebahagian begitupun sebaliknya (Utami, 2012). Oleh karena itu, berdasarkan penelitian Utami (2012), alasan religiusitas tidak dapat menjadi moderasi pada pengaruh kecemasan masa depan terhadap kesejahteraan subjektif pada penelitian ini jika individu hanya memahami religiusitas sebagai praktik agama yang hanya dilakukan mengikuti aturan tidak digunakan sebagai coping yang dapat membantu kehidupan sehari-hari.

Berdasarkan hasil penelitian, religiusitas Islam tidak dapat memoderasi pengaruh kecemasan akan masa depan terhadap kesejahteraan subjektif mahasiswa tingkat akhir Universitas Pendidikan Indonesia, maka dilakukan analisis pengaruh religiusitas terhadap kecemasan masa depan serta pengaruh religiusitas terhadap kesejahteraan subjektif untuk mengetahui peran religiusitas terhadap variabel-variabel tersebut.

\section{KESIMPULAN}

Berdasarkan hasil penelitian yang dilakukan ketika seseorang memiliki kecemasan yang tinggi maka kesejahteraan subjektifnya rendah. Kecemasan subjektif dan kesejahteraan subjektif tidak dapat dimoderasi oleh religiusitas Islam. Hal ini dikarenakan terdapat faktor lain yang menjadi pengaruh terhadapa hubungan antara kecemasan masa depan, kesejahteraan subjektif dan juga religiusitas Islam. Dari hasil tersebut dapat diartikan bahwa ketika kondisi religiusitas seseorang tinggi belum pasti dia memiliki kecemasan masa depan yang rendah dan kesejahteraan subjektif. Ketiga variabel ini terdapat faktor yang benar-benar mempengaruhi yaitu ideologi dan pemahaman serta penerapan konsep pada religiusitas individu. Individu bisa menjadi tidak cemas dan subjektif tinggi jika dia menempatkan agama sebagai penolong dalam hidupnya.

\section{SARAN}

Peneliti memiliki kekurangan dalam penelitiannya dikarenakan kesalahan awal peneliti dalam memilih subjek. Dikarenakan penelitian ini membahas mengenai peran religiusitas maka sebaiknya penelitian ini dilakukan pada orang-orang yang berada di lingkungan yang agamis dan mendapatkan ilmu agama setiap hari, contohnya pesantren.

\section{DAFTAR PUSTAKA}

Abdel-khalek, A. M. (2011). Religiosity, Subjective Well-Being, Self-Esteem, and Anxiety among Kuwait Muslim Adolescents. Mental Health, Religion and Culture, 14(2), 3741. https://doi.org/10.1080/13674670903456463

Abdel-Khalek, A. M. (2010). Quality of life, subjective well-being, and religiosity in Muslim college students. Quality of Life Research, 19(8), 1133-1143. https://doi.org/10.1007/s11136-010-9676-7

Abdel-Khalek, A. M., \& Lester, D. (2012). Constructions of religiosity, subjective wellbeing, anxiety, and depression in two cultures: Kuwait and USA. International Journal of Social Psychiatry, 58(2), 138-145. https://doi.org/10.1177/0020764010387545

Arnett, Jeffrey Jensen. (2000). Emerging adulthood: A theory of development from the late teens through the twenties. American Psychologist, Vol. 55, pp. 469-480. https://doi.org/10.1037/0003-066X.55.5.469

Beiter, R., Nash, R., McCrady, M., Rhoades, D., Linscomb, M., Clarahan, M., \& Sammut, 
S. (2015). The prevalence and correlates of depression, anxiety, and stress in a sample of college students. Journal of Affective Disorders, 173, 90-96. https://doi.org/10.1016/j.jad.2014.10.054

Blanco, C., Okuda, M., Wright, C., Hasin, D. S., Grant, B. F., Liu, S. M., \& Olfson, M. (2015). Mental Health of College Students and Their Non-College-Attending Peers. Arch Gen Psychiatry, 65(12), 1429-1437.

Busseri, M. A., \& Sadava, S. W. (2011). A Review of the Tripartite Structure of Subjective Well-Being: Implications for Conceptualization, Operationalization, Analysis, and Synthesis. Personality and Social Psychologi Review, 15(3), 290-314. https://doi.org/10.1177/1088868310391271

Cohen, A. B., Pierce, J. D., Chambers, J., Meade, R., Gorvine, B. J., \& Koenig, H. G. (2005). Intrinsic and extrinsic religiosity, belief in the afterlife, death anxiety, and life satisfaction in young Catholics and Protestants. Journal of Research in Personality, 39(3), 307-324. https://doi.org/10.1016/j.jrp.2004.02.005

Damer, D. E., Latimer, K. M., \& Porter, S. H. (2010). "Build your social confidence": A social anxiety group for college students. Journal for Specialists in Group Work, 35(1), 7-22. https://doi.org/10.1080/01933920903463510

Diener, E. (2006). Guidelines for National Indicators of Subjective Well Being and Ill Being. Applied Research in Quality of Life, 1, 151-157. https://doi.org/10.1007/s11482-0069007-x

Freitas, T. H., Hyphantis, T. N., Andreoulakis, E., Miranda, H. L., Alves, G. S., Souza, M. H., ... Carvalho, A. F. (2015). Religious coping and its influence on psychological distress, medication adherence, and quality of life in inflammatory bowel disease. Revista Brasileira de Psiquiatria, 37, 219-227. https://doi.org/10.1590/1516-44462014-1507

Ganga, N. S., \& Kutty, V. R. (2013). Influence of religion, religiosity and spirituality on positive mental health of young people. Mental Health, Religion and Culture, 16(4), 435-443. https://doi.org/10.1080/13674676.2012.697879

Guney, S., Kalafat, T., \& Boysan, M. (2010). Dimensions of mental health : life satisfaction , anxiety and depression: a preventive mental health study in Ankara University students population. Procedia Social and Behavior Sciences, 2, 1210-1213. https://doi.org/10.1016/j.sbspro.2010.03.174

Gutter, M., \& Copur, Z. (2011). Financial Behaviors and Financial Well-Being of College Students: Evidence from a National Survey. J Fam Econ Iss, 32, 699-714. https://doi.org/10.1007/s10834-011-9255-2

Huber, S., \& Huber, O. W. (2012). The Centrality of Religiosity Scale (CRS). Religions, 3(4), 710-724. https://doi.org/10.3390/rel3030710

Jong, J., Ross, R., Philip, T., Chang, S., Simons, N., Jong, J., ... Simons, N. (2017). The religious correlates of death anxiety: a systematic review and meta-analysis. Religion, Brain \& Behavior, O(0), 1-17. https://doi.org/10.1080/2153599X.2016.1238844

Kim, S., Kim, G., \& Ki, J. (2014). Effects of group art therapy combined with breath meditation on the subjective well-being of depressed and anxious adolescents. The Arts in Psychotherapy. https://doi.org/10.1016/j.aip.2014.10.002

Koenig, H. G., Larson, D. B., \& Larson, S. S. (2001). Religion and coping with serious medical illness. Annals of Pharmacotherapy, 35(3), 352-359. 
https://doi.org/10.1345/aph.10215

Lau, J. Y. F., Eley, T. C., \& Stevenson, J. (2006). Examining the state-trait anxiety relationship: A behavioural genetic approach. Journal of Abnormal Child Psychology, 34(1), 19-27. https://doi.org/10.1007/s10802-005-9006-7

Lindsey, C. (2014). Trait anxiety in college students: the role of the approval seeking schema and separation individuation. College Student Journal, 48(3), 407-418.

Longest, K. C., \& Smith, C. (2011). Conflicting or Compatible : Beliefs About Religion and Science Among Emerging Adults in the United States. Sosiological Forum, 26(4), 846869. https://doi.org/10.1111/j.1573-7861.2011.01287.x

Mahmoud, J. S. R., Staten, R. T., Lennie, T. A., \& Hall, L. A. (2015). The Relationships of Coping, Negative Thinking, Life Satisfaction, Social Support, and Selected Demographics With Anxiety of Young Adult College Students. Journal of Child and Adolescent Psychiatric Nursing, 28(2), 97-108. https://doi.org/10.1111/jcap.12109

Martin, L. (2016). Understanding the Quarter Life Crisis in Community College Student. Regent University.

Matzka, M., Mayer, H., Köck-Hódi, S., Moses-Passini, C., Dubey, C., Jahn, P., ... Eicher, M. (2016). Relationship between resilience, psychological distress and physical activity in cancer patients: A cross-sectional observation study. PLoS ONE, 11(4), 1-13. https://doi.org/10.1371/journal.pone.0154496

Miloyan, B., Pachana, N. A., \& Suddendorf, T. (2014). The future is here: A review of foresight systems in anxiety and depression. Cognition and Emotion, 28(5), 795-810. https://doi.org/10.1080/02699931.2013.863179

Mohammadzadeh, A., \& Najafi, M. (2018). The Comparison of Death Anxiety , Obsession , and Depression Between Muslim Population with Positive and Negative Religious Coping. Journal of Religion and Health, 0123456789. https://doi.org/10.1007/s10943018-0679-y

Murphy, M. (2011). Emerging adulthood in Ireland: Is the quarter-life crisis a common experience? Dublin Institute of Technology.

O’Rourke, E. J., Halpern, L. F., \& Vaysman, R. (2018). Examining the Relations Among Emerging Adult Coping, Executive Function, and Anxiety. Emerging Adulthood, 1-17. https://doi.org/10.1177/2167696818797531

Ozen, N. S., Ercan, I., Irgil, E., \& Sigirli, D. (2010). Anxiety prevalence and affecting factors among university students. Asia-Pacific Journal of Public Health, 22(1), 127-133. https://doi.org/10.1177/1010539509352803

Park, E. M., Deal, A. M., Check, D. K., Hanson, L. C., Reeder-hayes, K. E., Mayer, D. K., ... Rosenstein, D. L. (2015). Parenting concerns, quality of life , and psychological distress in patients with advanced cancer.

Peteet, J. R., \& Balboni, M. J. (1997). Spirituality and Religion in Oncology. American Cancer Society, 63(4), 280-289. https://doi.org/10.1002/caac.21187.

Ronen, T., Hamama, L., Rosenbaum, M., \& Mishely-Yarlap, A. (2014). Subjective WellBeing in Adolescence: The Role of Self-Control, Social Support, Age, Gender, and Familial Crisis. Journal of Happiness Studies. https://doi.org/10.1007/s10902-0149585-5

Rossi, N. E., \& Mebert, C. J. (n.d.). The Journal of Genetic Psychology: Research and Theory on Human Development Does a Quarterlife Crisis Exist? (January 2013), 37- 
41.

Saber, J., Mahmoud, R., Staten, R. T., Hall, L. A., \& Lennie, T. A. (2012). The Relationship among Young Adult College Students 'Depression, Anxiety, Stress, Demographics, Life Satisfaction , and Coping Styles. (2006), 149-156. https://doi.org/10.3109/01612840.2011.632708

Shiah, Y., Chang, F., Chiang, S., Lin, I., \& Tam, W. C. (2015). Religion and Health : Anxiety , Religiosity , Meaning. Journal Religion and Health, 54, 35-45. https://doi.org/10.1007/s10943-013-9781-3

Soleimani, M. A., Lehto, R. H., Negarandeh, R., Bahrami, N., \& Chan, Y. H. (2016). Death Anxiety and Quality of Life in Iranian Caregivers of Patients With Cancer. 00(0), 1-10. https://doi.org/10.1097/NCC.0000000000000355

Soysa, C. K., \& Wilcomb, C. J. (2013). Mindfulness, Self-compassion, Self-efficacy, and Gender as Predictors of Depression, Anxiety, Stress, and Well-being. Mindfulness. https://doi.org/10.1007/s12671-013-0247-1

Spielberger, C D, Gorsuch, R. L., Lushene, P. R., Vagg, P. R., \& Jacobs, A. G. (1972). Current Trends in Theory and Research on anxiety. Anxiety, 1, 3-19. https://doi.org/10.1002/9780470479216.corpsy0943

Spielberger, Charles D. (1972). Current Trends in Theory and Research on Anxiety. Anxiety, 1, 3-19. https://doi.org/10.1016/b978-0-12-657401-2.50008-3

Steinmayr, R., Crede, J., McElvany, N., \& Wirthwein, L.. ( 2016). Subjective Well-Being, Test Anxiety, Academic Achievement: Testing for Reciprocal Effect. Frontiers in Psychology, 6.

Sussman, S., \& Arnett, J. J. (2014). Emerging Adulthood: Developmental Period Facilitative of the Addictions. 37(2), 147-155. https://doi.org/10.1177/0163278714521812

Tanner, J. L. (2006a). Mental Health in Emerging Adulthood. SubStance, 1-15. https://doi.org/10.1093/oxfordhb/9780199795574.013.30

Tanner, J. L. (2006b). Mental Health in Emerging Adulthood. 1-15.

Tone, E. B., Goulding, S. M., \& Compton, M. T. (2011). Associations among perceptual anomalies, social anxiety, and paranoia in a college student sample. Psychiatry Research, 188(2), 258-263. https://doi.org/10.1016/j.psychres.2011.03.023

Twenge, J. M. (2000). The Age of Anxiety? Birth Cohort Change in Anxiety. 79(6), 10071021. https://doi.org/10.1097/MNH.0000000000000266

Zaleski, Z. (1996). Future anxiety: Concept, measurement, and preliminary research. Personality and Individual Differences, 21(2), 165-174. https://doi.org/10.1016/01918869(96)00070-0

Zaleski, Z. (2008). Future Orientation and Anxiety. In A. Strathman \& J. Joireman (Eds.), Understanding Behavior in The Context of Time: Theory, Research and Application (pp. 125-141). London: Taylor \& Francis e-Library. 